in vivo $34: 1893-1900(2020)$

doi:10.21873/invivo.11985

\title{
The ABO Blood Group Impacts the Survival of Patients Undergoing Pancreatoduodenectomy for Biliary Tract Cancer
}

\author{
SHOZO MORI, TAKU AOKI, KAZUMA TAGO, TAKAYUKI SHIMIZU, NOBUHIRO HARADA, \\ KYUNG-HWA PARK, YUHKI SAKURAOKA, TAKAYUKI SHIRAKI, YUKIHIRO ISO and KEIICHI KUBOTA \\ Department of Gastroenterological Surgery, Dokkyo Medical University, Tochigi, Japan
}

\begin{abstract}
Background/Aim: Although ABO blood group has been reported to be associated with the outcome of patients with pancreatic cancer, little is known about its impact on patients with biliary tract cancer (BTC). We evaluated the prognostic relevance of $A B O$ blood group in patients who had undergone resection of BTC. Patients and Methods: A total of 154 patients with BTC undergoing pancreatoduodenectomy were retrospectively reviewed. Associations between $A B O$ blood group and patient survival were evaluated by univariate and multivariate analysis. Results: The 5-year overall survival rate was higher in group $O$ patients $(n=46)$ than in other blood group patients $(n=108)$ (65.8\% vs. 47\%, $p=0.005)$. Multivariate analysis revealed that a non-O blood group was an independent risk factor for poor survival $(p=0.021)$. Conclusion: ABO blood group is associated with the prognosis of patients with resected BTC; group O patients have a better outcome.
\end{abstract}

The ABO blood group antigens are the most important alloantigens among the human blood group systems, being expressed not only on red blood cell membranes but also on the surfaces of several other cell types and tissues (1-3). The association between ABO blood group and cancer has been studied by a number of investigators since the mid-1900s (47); and several plausible mechanisms have been proposed to explain this association, including inflammation, immune response, intercellular adhesion, and cellular membrane signaling (3, 8-10). In fact, the influence of ABO blood group has been reported in various types of malignancy,

This article is freely accessible online.

Correspondence to: Shozo Mori, MD, Ph.D., Department of Gastroenterological Surgery, Dokkyo Medical University, 880 Kitakobayashi, Mibu, Shimotsuga, Tochigi, 321-0293, Japan. Tel: +81 282872158, Fax: +81 282866317, e-mail: s-mori@dokkyomed.ac.jp

Key Words: ABO blood group, biliary tract cancer, pancreatoduodenectomy, prognosis. including cancers of the gastrointestinal tract, urinary tract, respiratory tract, and breast $(3,6)$. In the pancreato-biliary field, a lower incidence of pancreatic cancer in blood group $\mathrm{O}$ individuals was revealed in a two-stage genome-wide association study (GWAS) (11). Some studies have also suggested that blood group $\mathrm{O}$ confers a more favorable prognosis than non-O blood groups in patients with pancreatic cancer $(12,13)$. With regard to biliary tract cancer (BTC), it remains unclear if $\mathrm{ABO}$ blood group impacts the clinical outcome. Because BTC is a relatively rare malignancy (14-16), the relationship between blood groups and outcome might be difficult to assess because of the small number of cases. Therefore, the aim of this study was to investigate the associations between the $\mathrm{ABO}$ blood groups and outcomes of patients with BTC who had undergone pancreatoduodenectomy (PD), and whether blood group $\mathrm{O}$ is associated with a favorable prognosis.

\section{Patients and Methods}

A total of 161 consecutive patients with BTC underwent PD with curative intent at the Department of Gastroenterological Surgery, Dokkyo Medical University Hospital, between June 2000 and May 2017. Four patients who died of postoperative complications in the hospital and 3 patients with distant metastases affecting the liver and para-aortic lymph nodes at the time of surgery were excluded, because the aim of this study was to evaluate the long-term outcome. Finally, 154 patients were retrospectively reviewed. This study was approved by the ethics committee of Dokkyo Medical University (R-13-9J).

Distal cholangiocarcinoma (DCC) was defined as cholangiocarcinoma with an epicenter located in the common bile duct below the confluence of the cystic duct and above the ampulla of Vater (17). A carcinoma arising from the ampullary complex, distal to the confluence of the common bile and pancreatic duct, was defined as Ampulla of Vater cancer (AVC) (18).

Histopathological reviews of the resected specimens were performed by pathologists. The tumors were classified according to the Sixth Edition of the Japanese Rules for Cancer of the Biliary Tract and the Seventh Edition of the AJCC Staging Manual $(17,19)$.

Conventional PD or subtotal stomach-preserving PD with regional lymph node dissection were routinely performed $(20,21)$. Postoperative complications were classified according to the 
Clavien-Dindo classification (22). Patients with Grade III or IV complications were included in the complication group. No patients received neoadjuvant chemotherapy. Adjuvant chemotherapy was used according to each patient's decision after his/her informed consent, since no adjuvant chemotherapy has yet been established for BTC in Japan (23-25).

After surgery, the patients visited the hospital once a month for the initial 12 months and at 2- to 3-month intervals after surgery. Tumor markers, including carcinoembryonic antigen (CEA) and carbohydrate antigen 19-9 (CA19-9) were examined at each visit. Patients were monitored by contrast-enhanced computed tomography of the chest and abdomen at 3-month intervals for the initial 12 months and at 4-month intervals thereafter.

SPSS version 25.0 (IBM Japan, Tokyo, Japan) was used for all statistical analyses. The $\chi^{2}$ test was used for categorical data. Survival curves were created by the Kaplan-Meier method and compared by the log-rank test. The median follow-up period was calculated as the interval between the date of surgery and the date of last follow-up or death. The Cox proportional hazards model with forward stepwise selection was used for multivariate analysis. Differences with $p<0.05$ were considered statistically significant.

\section{Results}

A total of 154 patients with BTC who underwent pancreatoduodenectomy were eligible for analysis. Among them, 90 (58.4\%) had DCC and 64 (41.6\%) had AVC. There were 46 blood group O patients $(29.9 \%)$ and 108 non-O patients $(70.1 \%)$ [52 group A (33.8\%), $48 \mathrm{~B}(31.2 \%)$, and 8 $\mathrm{AB}(5.1 \%)]$. There were 93 men $(60.4 \%)$ and 61 women $(39.6 \%)$ with a median age of 70 years (range $=35-85$ years). The median follow-up period was 44 months (range $=4-233$ months) for the entire patient group. The median operative time and blood loss were $496 \mathrm{~min}$ (range=232-957 $\mathrm{min}$ ) and $581 \mathrm{ml}$ (range=76-3212 $\mathrm{ml}$ ), respectively.

PD with portal vein resection to achieve curative resection was undertaken in 8 patients [group $\mathrm{O}(\mathrm{n}=1)$ and non-O $(\mathrm{n}=7)]$. Postoperative complications (Clavien-Dindo classification grade III or IV) were observed in 40 patients (26\%). The median postoperative hospital stay was 37 days (range $=10-168$ days). The clinicopathological characteristics in relation to the ABO blood group are summarized in Table I. The differences between any of the variables were not significant, except for the pathological lymph node status in the blood group O and non-O patients. Differences between surgical variables such as operative time, blood loss, postoperative complications, and postoperative hospital stay for the blood group $\mathrm{O}$ and non-O patients were not significant [median 496 min vs. $492 \mathrm{~min}, p=0.825$; median $568 \mathrm{ml} v s .581 \mathrm{ml}, p=0.810 ; \mathrm{n}=12(26 \%)$ vs. $\mathrm{n}=28(26 \%)$, $p=0.983$; and median 37 days vs. 38 days, $p=0.417$; respectively].

Differences between the proportions of patients with DCC and AVC making up blood group $\mathrm{O}$ and non-O patients [Group O: $\mathrm{n}=31(67.4 \%)$ DCC and $\mathrm{n}=15$ (32.6\%) AVC vs.
Table I. Clinicopathological characteristics of patients stratified by ABO blood group.

\begin{tabular}{|c|c|c|c|c|c|}
\hline \multirow[t]{2}{*}{ Variables } & \multicolumn{4}{|c|}{$\mathrm{ABO}$ blood group } & \multirow[t]{2}{*}{$p$-Value } \\
\hline & $O(n=46)$ & $A(n=52)$ & B $(n=48)$ & $\mathrm{AB}(\mathrm{n}=8)$ & \\
\hline Age (years) & & & & & 0.062 \\
\hline$<70$ & $28(61 \%)$ & $26(50 \%)$ & $19(40 \%)$ & $3(37 \%)$ & \\
\hline$>70$ & $18(39 \%)$ & $26(50 \%)$ & $29(60 \%)$ & $5(63 \%)$ & \\
\hline Gender & & & & & 0.660 \\
\hline Female & $17(37 \%)$ & $21(40 \%)$ & $19(40 \%)$ & $4(50 \%)$ & \\
\hline Male & $29(63 \%)$ & $31(60 \%)$ & $29(60 \%)$ & $4(50 \%)$ & \\
\hline CEA (ng/ml) & & & & & 0.514 \\
\hline$<5$ & $41(89 \%)$ & $46(88 \%)$ & $39(81 \%)$ & $7(88 \%)$ & \\
\hline$>5$ & $5(11 \%)$ & $6(12 \%)$ & $9(19 \%)$ & $1(12 \%)$ & \\
\hline CA19-9 (U/ml) & & & & & 0.527 \\
\hline$<37$ & $23(50 \%)$ & $33(63 \%)$ & $24(50 \%)$ & $3(37 \%)$ & \\
\hline$>37$ & $23(50 \%)$ & $19(37 \%)$ & $24(50 \%)$ & $5(63 \%)$ & \\
\hline Histopathology & & & & & 0.665 \\
\hline Pap or wel & $17(37 \%)$ & $21(40 \%)$ & $13(27 \%)$ & $2(25 \%)$ & \\
\hline Mod or por & $29(63 \%)$ & $31(60 \%)$ & $35(73 \%)$ & $6(75 \%)$ & \\
\hline pT status & & & & & 0.882 \\
\hline $\mathrm{T} 1,2$ & $27(59 \%)$ & $32(62 \%)$ & $24(50 \%)$ & $6(75 \%)$ & \\
\hline $\mathrm{T} 3,4$ & $19(41 \%)$ & $20(38 \%)$ & $24(50 \%)$ & $2(25 \%)$ & \\
\hline $\mathrm{pN}$ status & & & & & 0.014 \\
\hline Negative & $36(78 \%)$ & $28(54 \%)$ & $29(60 \%)$ & $5(63 \%)$ & \\
\hline Positive & $10(22 \%)$ & $24(46 \%)$ & $19(40 \%)$ & $3(37 \%)$ & \\
\hline pStage & & & & & 0.341 \\
\hline I & $23(50 \%)$ & $22(42 \%)$ & $18(37 \%)$ & $5(63 \%)$ & \\
\hline II, III & $23(50 \%)$ & $30(58 \%)$ & $30(63 \%)$ & $3(37 \%)$ & \\
\hline Resection margi & & & & & 0.718 \\
\hline Negative & $41(89 \%)$ & $47(90 \%)$ & $41(85 \%)$ & $6(75 \%)$ & \\
\hline Positive & $5(11 \%)$ & $5(10 \%)$ & $7(15 \%)$ & $2(25 \%)$ & \\
\hline
\end{tabular}

CA19-9: Carbohydrate antigen 19-9; CEA: carcinoembryonic antigen; Mod: moderately differentiated; Pap: papillary; Por: poorly differentiated; Wel: well differentiated. $* \chi^{2}$ test (O blood group $v s$. NonO blood group).

Non-O: $\mathrm{n}=59$ (54.6\%) DCC and $\mathrm{n}=49$ (45.4\%) AVC, $p=0.141]$ were not significant. Adjuvant chemotherapy agents such as gemcitabine $(n=38)$, gemcitabine plus cisplatin $(n=18), S-1(n=3)$ and others $(n=5)$ were administered to 14 , 3,1 , and 4 blood group $O$ patients and to $24,15,2$ and 1 nonO patients, respectively. There was no significant difference between the blood group $\mathrm{O}$ and non-O patients with regard to adjuvant chemotherapy agents $(p=0.303)$.

Overall survival rate according to ABO blood group. The 5year overall survival (OS) rates for the $\mathrm{O}, \mathrm{A}, \mathrm{B}$ and $\mathrm{AB}$ group patients were $65.8 \%(n=46), 40.3 \%(n=52), 56.9 \%$ $(\mathrm{n}=48)$, and $37.5 \%(\mathrm{n}=8)$, respectively; $[p=0.006(\mathrm{O} v s . \mathrm{A})$, $p=0.061(\mathrm{O} v s . \mathrm{B})$, and $p=0.013(\mathrm{O} v s . \mathrm{AB})]$ (Figure 1). The 5 -year OS rates in the blood group $\mathrm{O}(\mathrm{n}=46)$ and non-O $(\mathrm{n}=108)$ patients were $65.8 \%$ vs. $47 \%$, respectively $(p=0.005)$. The association between ABO blood group and patient survival was significant. 


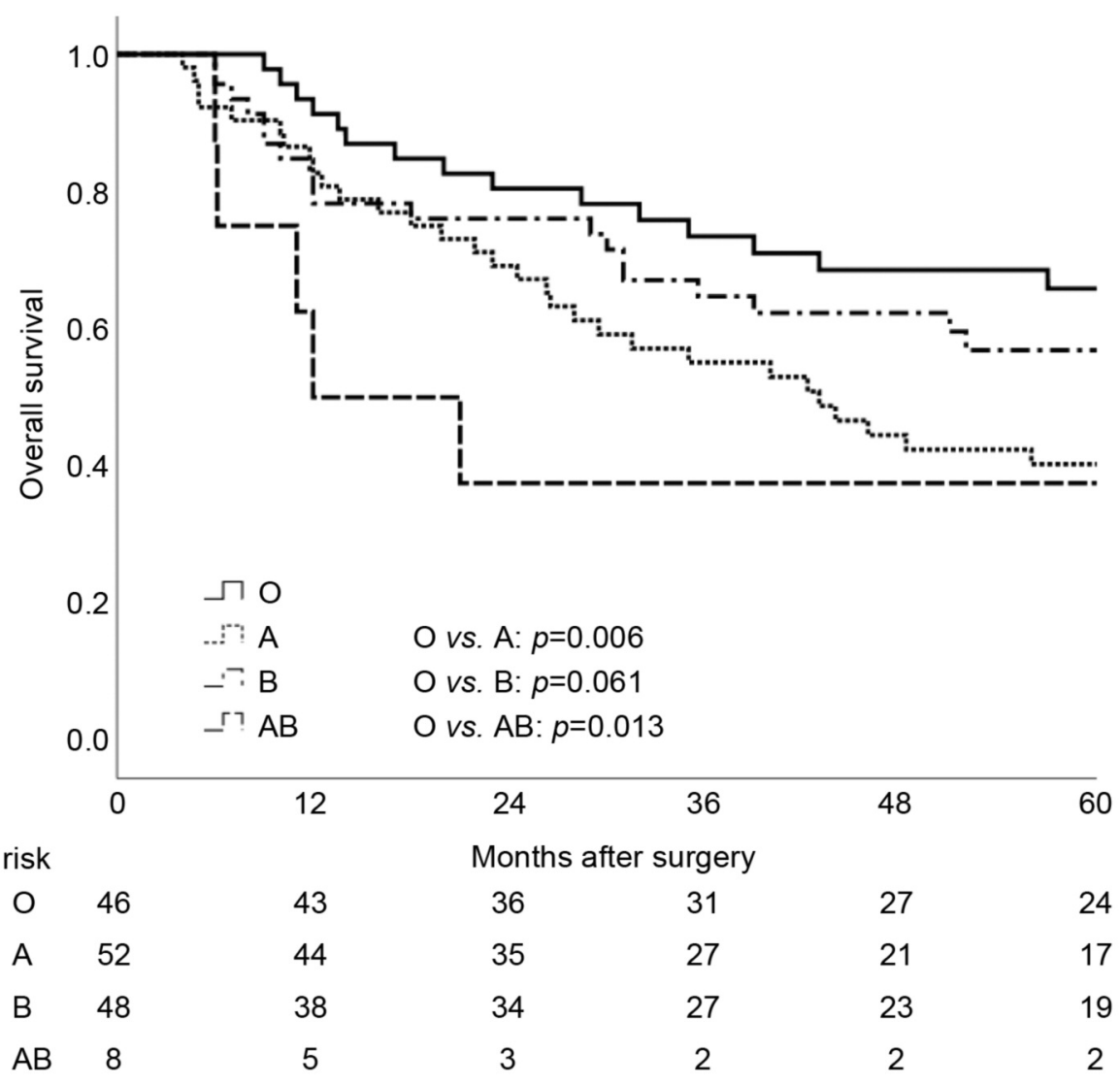

Figure 1. Overall survival (OS) stratified by the ABO blood groups. The 5-year OS rates for the $O, A, B$ and AB group patients were $65.8 \%(n=46)$, $40.3 \%(n=52), 56.9 \%(n=48)$, and $37.5 \%(n=8)$, respectively; $[p=0.006(O$ vs. $A), p=0.061(O v s . B)$, and $p=0.013(O$ vs. $A B)]$.

Overall survival rate according to $A B O$ blood group in patients with or without lymph node metastasis. In patients negative for lymph node metastasis, the 5-year OS rates for the $\mathrm{O}, \mathrm{A}, \mathrm{B}$ and $\mathrm{AB}$ group patients were $65.5 \%(\mathrm{n}=36)$, $52.9 \%(\mathrm{n}=28), 57.7 \%(\mathrm{n}=29)$, and $60 \%(\mathrm{n}=5)$, respectively; $[p=0.339$ (O vs. A), $p=0.332$ (O vs. B), and $p=0.483$ (O vs. $\mathrm{AB})$ ] (Figure 2A). The 5-year OS rates in blood group $\mathrm{O}$ $(\mathrm{n}=36) v s$. non-O $(\mathrm{n}=62)$ patients were $65.5 \%$ vs. $55.3 \%$, respectively $(p=0.230)$. In patients positive for lymph node metastasis, the 5-year OS rates for the $\mathrm{O}, \mathrm{A}, \mathrm{B}$ and $\mathrm{AB}$ group patients were $66.7 \%(n=10), 25 \%(n=24), 55.8 \%(n=19)$, and $0 \%(\mathrm{n}=3)$, respectively; $[p=0.009$ (O vs. A), $p=0.111$ (O vs. $\mathrm{B})$, and $p<0.001(\mathrm{O} v s . \mathrm{AB})]$ (Figure 2B). The 5-year OS rates in blood group $\mathrm{O}(\mathrm{n}=10) v s$. non-O $(\mathrm{n}=46)$ patients were $66.7 \%$ vs. $35.8 \%$, respectively $(p=0.016)$. The association between ABO blood group and patient survival in patients positive for lymph node metastasis was significant.

Risk factors for survival. Table II shows the results of the uni- and multivariate analysis of risk factors for OS. Seven of 10 factors were found to be significant by univariate analysis: non-O blood group, CEA $>5 \mathrm{ng} / \mathrm{ml}, \mathrm{CA} 19-9>37$ $\mathrm{U} / \mathrm{ml}$, histology (mod or por), pT3 or pT4, lymph node metastases (+), and resection margin (+). Multivariate analysis revealed that non-O blood group [hazard ratio $(\mathrm{HR})=1.811 ; 95 \%$ confidence interval $(\mathrm{CI})=1.093-3.001$; $p=0.021], \mathrm{CEA}>5 \mathrm{ng} / \mathrm{ml}(\mathrm{HR}=2.282 ; 95 \% \mathrm{CI}=1.294-4.022$; $p=0.004)$, histopathology $(\bmod$ or $\operatorname{por}) \quad(\mathrm{HR}=1.860$; $95 \% \mathrm{CI}=1.145-3.022 ; p=0.012)$, and resection margin $(+)$ $(\mathrm{HR}=2.762 ; \quad 95 \% \mathrm{CI}=1.558-4.895 ; \quad p=0.001) \quad$ were independent risk factors for poor OS.

\section{Discussion}

This study clearly demonstrated a relationship between ABO blood group and the outcome of patients with BTC who had undergone $\mathrm{PD}$. Patients with blood group $\mathrm{O}$ had the best 5year OS rate, followed in order by blood groups B, A, and $\mathrm{AB}$ (Figure 1). In addition, having a non-O blood type was shown to be a risk factor for poor survival by multivariate analysis (Table II). These results are similar to those of 
A Negative for lymph node metastasis

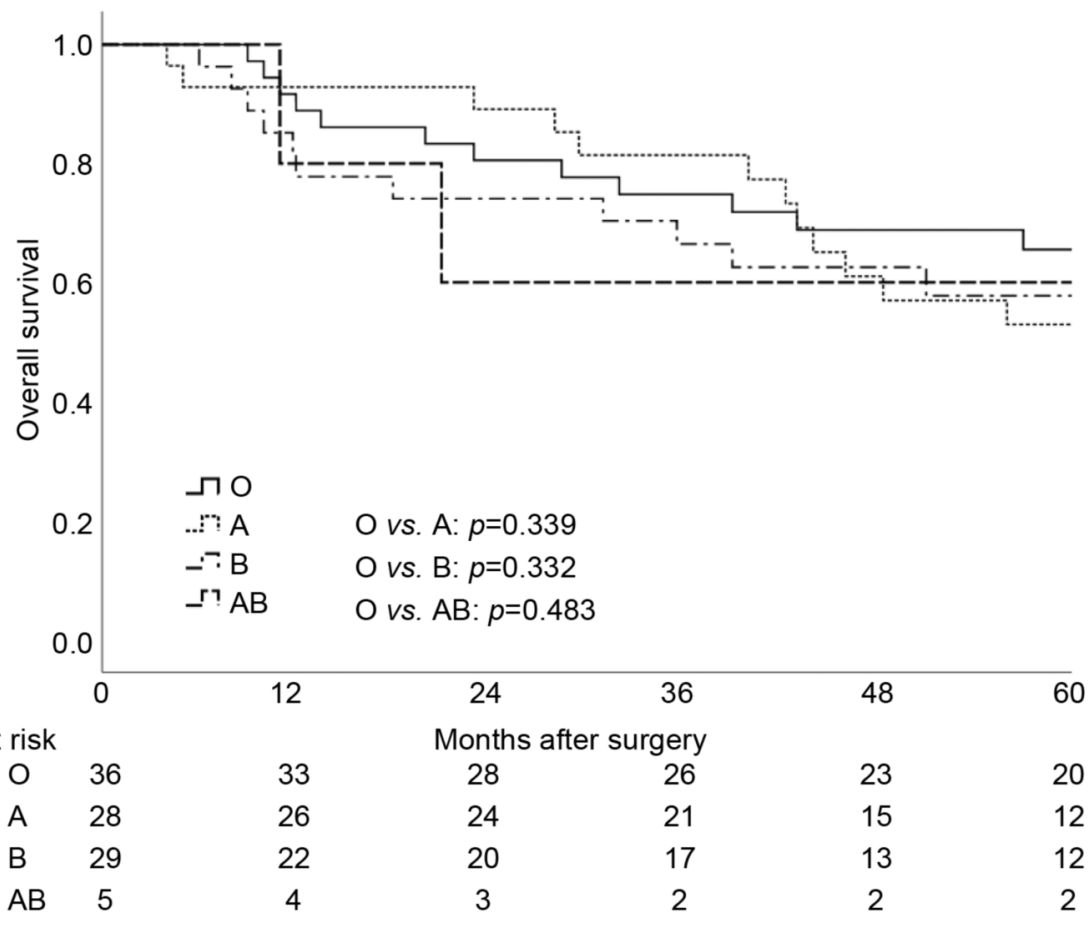

\section{B Positive for lymph node metastasis}

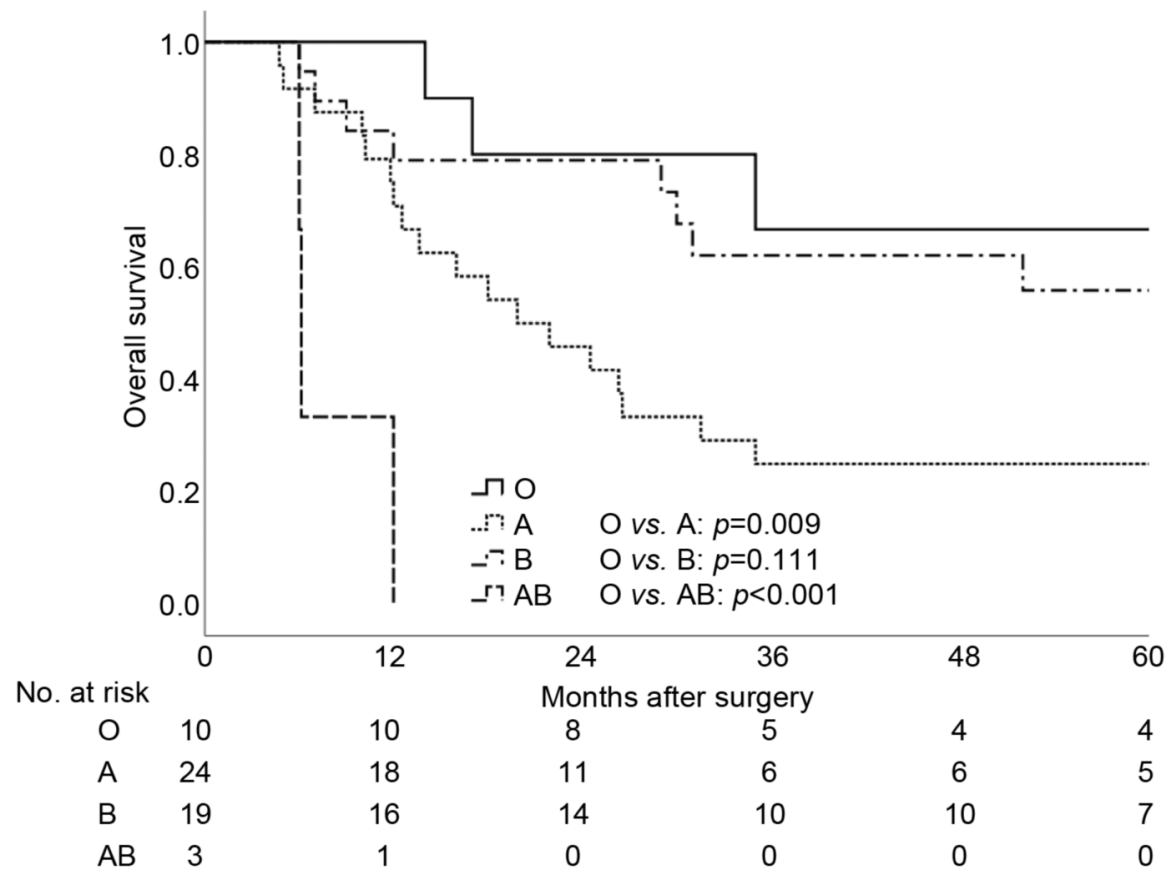

Figure 2. Overall survival (OS) stratified by the ABO blood groups in patients negative (A) or positive (B) for lymph node metastasis. (A) In patients negative for lymph node metastasis, the 5-year OS rates for the $O, A, B$ and $A B$ group patients were $65.5 \%(n=36), 52.9 \%(n=28), 57.7 \%(n=29)$, and $60 \%(n=5)$, respectively; $[p=0.339(O$ vs. $A), p=0.332(O$ vs. $B)$, and $p=0.483(O$ vs. AB) ]. The 5-year OS rates in blood group $O(n=36) v s$. non- $O(n=62)$ patients were $65.5 \% \mathrm{vs.} 55.3 \%$, respectively; $(p=0.230)$. (B) In patients positive for lymph node metastasis, the 5 -year OS rates for the $O, A, B$ and $A B$ group patients were $66.7 \%(n=10), 25 \%(n=24), 55.8 \%(n=19)$, and $0 \%(n=3)$, respectively; $[p=0.009(O v s . A), p=0.111(O$ vs. $B)$, and $p<0.001(O$ vs. $A B)]$. 
Table II. Uni- and multivariate analyses of risk factors for survival of patients who underwent surgery for biliary tract cancer.

\begin{tabular}{|c|c|c|c|c|c|}
\hline \multirow[b]{2}{*}{ Variables } & \multirow[b]{2}{*}{$\mathrm{n}$} & \multirow{2}{*}{$\frac{\text { Univariate }}{p \text {-Value* }}$} & \multicolumn{3}{|c|}{ Multivariate } \\
\hline & & & $\mathrm{HR}$ & $95 \% \mathrm{CI}$ & $p$-Value ${ }^{\dagger}$ \\
\hline Age $\geq 70$ years & 78 & 0.157 & & & \\
\hline Male & 93 & 0.077 & & & \\
\hline Non-O blood group & 46 & 0.005 & 1.811 & $1.093-3.001$ & 0.021 \\
\hline $\mathrm{CEA}>5 \mathrm{ng} / \mathrm{ml}$ & 21 & $<0.001$ & 2.282 & $1.294-4.022$ & 0.004 \\
\hline CA19-9 >37 U/ml & 71 & 0.014 & - & - & - \\
\hline $\begin{array}{l}\text { Histopathology } \\
\text { (mod or por) }\end{array}$ & 101 & 0.004 & 1.860 & $1.145-3.022$ & 0.012 \\
\hline pT3, 4 & 65 & 0.010 & - & - & - \\
\hline LN metastases $(+)$ & 56 & 0.006 & - & - & - \\
\hline Resection margin $(+)$ & 19 & $<0.001$ & 2.762 & $1.558-4.895$ & 0.001 \\
\hline $\begin{array}{l}\text { Adjuvant } \\
\text { chemotherapy (+) }\end{array}$ & 64 & 0.888 & & & \\
\hline
\end{tabular}

CA19-9: Carbohydrate antigen 19-9; CEA: carcinoembryonic antigen; CI: confidence interval; HR: hazard ratio; Mod: moderately differentiated; Por: poorly differentiated. ${ }^{*}$ Log-rank test. ${ }^{\dagger}$ Cox proportional hazard model.

previous studies reporting that blood group $\mathrm{O}$ patients with pancreatic cancer had a better prognosis than patients with other blood types in the ABO blood group $(12,13)$. To our knowledge, this is the first report of a study using KaplanMeier analysis with log-rank test and multivariate analysis to evaluate the impact of $\mathrm{ABO}$ blood group status on the outcome of patients with BTC.

Several plausible mechanisms could account for the association between ABO blood group antigens and cancer development and progression (3, 8-10). Glycosyltransferase is encoded by the ABO gene located on chromosome $9 \mathrm{q} 34$. It catalyzes $\mathrm{N}$-acetylgalactosamine or $\mathrm{D}$-galactose to the common precursor, $\mathrm{H}$ antigen, which is eventually converted to the $\mathrm{A}$ or $\mathrm{B}$ antigen (3). The $\mathrm{O}$ variant encodes a nonfunctional glycosyltransferase (3). Changes in the enzymatic activity of $\mathrm{ABO}$ glycosyltransferase play an important role in the activation of adhesion molecules, intracellular signaling, and determination of the level of von Willebrand factor (VWF), thereby affecting tumor growth and spread (3, 8-10). VWF is a multimeric glycoprotein, which is synthesized in endothelial cells, and is one of several platelet adhesion ligands that could potentially modulate cancer development and metastasis $(3,8)$. The VWF antigen level in adults is, on average, about $25 \%$ to $30 \%$ lower in blood group $\mathrm{O}$ individuals than in non-O individuals $(26,27)$. Liu et al. (8) have reported that the level of VWF is significantly higher in lung cancer patients with distant metastasis than in those without distant metastasis and in healthy controls. Moreover, significantly increased plasma VWF levels have been observed in non- $\mathrm{O}$ individuals relative to $\mathrm{O}$ group individuals.
In patients with glioblastoma, increased VWF levels are related to a three-fold higher risk of death and a reduced likelihood of 1-year survival (28). These results indicate that an increased VWF level might facilitate the invasiveness and metastasis of tumors.

$\mathrm{ABO}$ gene was recently reported to affect the circulating levels of adhesion molecules such as soluble intercellular adhesion molecule-1 (sICAM-1), E-selectin, and P-selectin, which participate in inflammatory conditions $(3,29,30)$. Cancer and inflammation are known to be closely associated (10). Significantly decreased levels of sICAM-1 expression have been observed in non-O blood group patients (especially those with blood group A) compared with blood group $\mathrm{O}$ patients $(9,31,32)$. Low levels of sICAM- 1 might promote tumor spread and distant metastasis.

Several studies have reported an association between ABO blood group and the risk of pancreatic cancer $(11,33,34)$. An association between a locus on $9 q 34$ marked by the single nucleotide polymorphism (SNP) rs505922 and pancreatic cancer has been confirmed in a two-stage GWAS (11). Blood group O individuals were found to have a lower risk of pancreatic cancer than group A and B individuals. In the clinical setting, blood group $\mathrm{O}$ patients have been shown to have a better outcome than non-O patients $(12,13)$. Krawczyk et al. (35) investigated the relationship between the development of cholangiocarcinoma and the $\mathrm{ABO}$ variant rs505922 in 180 individuals with cholangiocarcinoma and 350 cholangiocarcinoma-free controls. They suggested that although the association between this SNP and cholangiocarcinoma did not reach significance in association tests and regression analysis, the presence of HardyWeinberg disequilibrium might be indicative of a possible association, especially in patients with intrahepatic cholangiocarcinoma. Additional studies of large cohorts that explore the differences in the potential risk of cholangiocarcinoma among individual blood groups might help to clarify the underlying mechanisms.

Phenotypic changes such as alterations in the expression of blood-group-related antigens are thought to be associated with tumor aggressiveness or prognosis in many malignancies $(36,37)$. In an immunohistochemical study, Minato et al. (38) investigated the expression of bloodgroup-related antigens in patients with cholangiocarcinoma, and the results suggested that both the expression and intracellular distribution of such antigens were related to the histological grade of the cholangiocarcinoma specimens. Alterations in the intracellular localization of these antigens might reflect the biological behavior of carcinoma cells. In the context of the prognosis of patients with cholangiocarcinoma, these findings are intriguing.

The relationship between Rhesus factor in blood group and oncological outcomes was not evaluated in this study, because an only patient was Rhesus-negative. D'Andrea et 
al. (39) reported that Rhesus factor was not associated with oncological outcomes for non-metastatic urothelial carcinoma of the bladder on multivariate analysis.

In patients negative for lymph node metastasis $(n=98)$, the difference between the 5-year OS rates of blood group $\mathrm{O}$ and non-O patients was not significant $(65.5 \%$ vs. $55.3 \%$, $p=0.230$ ). However, in patients positive for lymph node metastasis $(n=56)$, the 5 -year OS rate of blood group $\mathrm{O}$ patients was significantly higher than that of the blood group non-O patients (66.7\% vs. $35.8 \%$, respectively; $p=0.016)$. Although univariate analysis showed that adjuvant chemotherapy did not impact survival ( $p=0.888$ ) (Table II), among patients receiving adjuvant chemotherapy $(n=64)$, group $O$ patients $(n=22)$ obtained a better outcome than nonO patients $(n=42)(5$-year OS rate: $62 \%$ vs. $43.5 \%, p=0.030)$. These results suggest that stratification of patients by ABO blood group might be useful in future clinical studies designed to estimate the efficacy of adjuvant chemotherapy in patients who underwent resection of BTC.

Our study has limitations. This was a single-center retrospective study that analyzed data in a Japanese population only. In addition, the number of enrolled study patients was small. Therefore, additional prospective studies with larger numbers of patients are needed to confirm the association between ABO blood group and the outcome of patients with BTC. In addition, experimental studies are needed to clarify the underlying mechanisms involved in the impact of blood type on outcome.

In conclusion, our results suggest a significant association between $\mathrm{ABO}$ blood group and the survival of patients with BTC who have undergone PD. Patients with blood type O are more likely to have better survival than patients with a non-O blood type.

\section{Conflicts of Interest}

The Authors have no conflicts of interest to declare regarding this study.

\section{Authors' Contributions}

Study concept and design: S.M.; Drafting of the manuscript: S.M.; Data collection: K.T., T.S., N.H., K.P., Y.S., T.S., and Y.I.; Critical revision of the manuscript: T.A.; Study supervision: K.K.

\section{References}

1 Nakanuma Y and Sasaki M: Expression of blood group-related antigens in the intrahepatic biliary tree and hepatocytes in normal livers and various hepatobiliary diseases. Hepatology 10(2): 174-178, 1989. PMID: 2744729. DOI: 10.1002/hep. 1840100209

2 Ravn V and Dabelsteen E: Tissue distribution of histo-blood group antigens. APMIS 108(1): 1-28, 2000. PMID: 10698081. DOI: $10.1034 /$ j.1600-0463.2000.d01-1.x
3 Franchini M, Liumbruno GM and Lippi G: The prognostic value of ABO blood group in cancer patients. Blood Transfus 14(5): 434-440, 2016. PMID: 26674825. DOI: 10.2450/2015.0164-15

4 Marcus DM: The ABO and Lewis blood-group system. Immunochemistry, genetics and relation to human disease. N Engl J Med 280(18): 994-1006, 1969. PMID: 4888078. DOI: 10.1056/NEJM196905012801806

5 Aird I, Bentall $\mathrm{HH}$ and Roberts JA: A relationship between cancer of stomach and the ABO blood groups. Br Med J 1(4814): 799-801, 1953. PMID: 13032504. DOI: 10.1136/ bmj.1.4814.799

6 Vasan SK, Hwang J, Rostgaard K, Nyrén O, Ullum H, Pedersen OBV, Erikstrup C, Melbye M, Hjalgrim H, Pawitan Y and Edgren $\mathrm{G}$ : $\mathrm{ABO}$ blood group and risk of cancer: A register-based cohort study of 1.6 million blood donors. Cancer Epidemiol 44: 40-43, 2016. PMID: 27459465. DOI: 10.1016/j.canep.2016.06.005

7 Iodice S, Maisonneuve P, Botteri E, Sandri MT and Lowenfels AB: ABO blood group and cancer. Eur J Cancer 46(18): 33453350, 2010. PMID: 20833034. DOI: 10.1016/j.ejca.2010.08.009

8 Liu X, Chen X, Yang J and Guo R: Association of ABO blood groups with von Willebrand factor, factor VIII and ADAMTS13 in patients with lung cancer. Oncol Lett 14(3): 3787-3794, 2017. PMID: 28927148. DOI: 10.3892/ol.2017.6619

9 Witkowska AM and Borawska $\mathrm{MH}$ : Soluble intercellular adhesion molecule-1 (sICAM-1): an overview. Eur Cytokine Netw 15(2): 91-98, 2004. PMID: 15319166.

10 Grivennikov SI, Greten FR and Karin M: Immunity, inflammation, and cancer. Cell 140(6): 883-899, 2010. PMID: 20303878. DOI: 10.1016/j.cell.2010.01.025

11 Amundadottir L, Kraft P, Stolzenberg-Solomon RZ, Fuchs CS, Petersen GM, Arslan AA, Bueno-de-Mesquita HB, Gross M, Helzlsouer K, Jacobs EJ, LaCroix A, Zheng W, Albanes D, Bamlet W, Berg CD, Berrino F, Bingham S, Buring JE, Bracci PM, Canzian F, Clavel-Chapelon F, Clipp S, Cotterchio M, de Andrade M, Duell EJ, Fox JW Jr, Gallinger S, Gaziano JM, Giovannucci EL, Goggins M, González CA, Hallmans G, Hankinson SE, Hassan M, Holly EA, Hunter DJ, Hutchinson A, Jackson R, Jacobs KB, Jenab M, Kaaks R, Klein AP, Kooperberg C, Kurtz RC, Li D, Lynch SM, Mandelson M, McWilliams RR, Mendelsohn JB, Michaud DS, Olson SH, Overvad K, Patel AV, Peeters PH, Rajkovic A, Riboli E, Risch HA, Shu XO, Thomas G, Tobias GS, Trichopoulos D, Van Den Eeden SK, Virtamo J, Wactawski-Wende J, Wolpin BM, Yu H, Yu K, ZeleniuchJacquotte A, Chanock SJ, Hartge P and Hoover RN: Genomewide association study identifies variants in the $\mathrm{ABO}$ locus associated with susceptibility to pancreatic cancer. Nat Genet 41(9): 986-990, 2009. PMID: 19648918. DOI: 10.1038/ng.429

12 Rahbari NN, Bork U, Hinz U, Leo A, Kirchberg J, Koch M, Büchler MW and Weitz J: ABO blood group and prognosis in patients with pancreatic cancer. BMC Cancer 12: 319, 2012. PMID: 22838843. DOI: 10.1186/1471-2407-12-319

13 Ben Q, Wang K, Yuan Y and Li Z: Pancreatic cancer incidence and outcome in relation to $\mathrm{ABO}$ blood groups among Han Chinese patients: a case-control study. Int J Cancer 128(5): 1179-1186, 2011. PMID: 20473916. DOI: 10.1002/ijc. 25426

14 Komaya K, Ebata T, Shirai K, Ohira S, Morofuji N, Akutagawa A, Yamaguchi R and Nagino M; Nagoya Surgical Oncology Group: Recurrence after resection with curative intent for distal cholangiocarcinoma. Br J Surg 104(4): 426-433, 2017. PMID: 28138968. DOI: $10.1002 /$ bjs.10452 
15 Shaib $Y$ and El-Serag HB: The epidemiology of cholangiocarcinoma. Semin Liver Dis 24(2): 115-125, 2004. PMID: 15192785. DOI: 10.1055/s-2004-828889

16 Bektas H, Yeyrek C, Kleine M, Vondran FW, Timrott K, Schweitzer $\mathrm{N}$, Vogel A, Jäger MD, Schrem H, Klempnauer J and Kousoulas L: Surgical treatment for intrahepatic cholangiocarcinoma in Europe: a single center experience. J Hepatobiliary Pancreat Sci 22(2): 131137, 2015. PMID: 25159731. DOI: 10.1002/jhbp.158

17 Edge SB, Byrd DR, Compton CC, Fritz AG, Greene FL and Trotti A (eds.): AJCC Cancer Staging Manual (7th edn). Springer: New York, 2010.

18 Ahn DH and Bekaii-Saab T: Ampullary cancer: an overview. Am Soc Clin Oncol Educ Book 2014: 112-115, 2014. PMID: 24857067. DOI: 10.14694/EdBook_AM.2014.34.112

19 Japanese Society of Biliary Surgery: General Rules for Surgical and Pathological Studies on Cancer of the Biliary Tract (6th edn) (in Japanese). Kanehara: Tokyo, 2013.

20 Shimoda M, Kubota K, Shimizu T and Katoh M: Randomized clinical trial of adjuvant chemotherapy with $\mathrm{S}-1$ versus gemcitabine after pancreatic cancer resection. Br J Surg 102(7): 746-754, 2015. PMID: 25833230. DOI: 10.1002/bjs.9775

21 Shimoda M, Kubota K, Katoh M and Kita J: Effect of Billroth II or Roux-en-Y reconstruction for the gastrojejunostomy on delayed gastric emptying after pancreaticoduodenectomy: a randomized controlled study. Ann Surg 257(5): 938-942, 2013. PMID: 23579543. DOI: 10.1097/SLA.0b013e31826c3f90

22 Clavien PA, Barkun J, de Oliveira ML, Vauthey JN, Dindo D, Schulick RD, de Santibañes E, Pekolj J, Slankamenac K, Bassi C, Graf R, Vonlanthen R, Padbury R, Cameron JL and Makuuchi M: The Clavien-Dindo classification of surgical complications: five-year experience. Ann Surg 250(2): 187-196, 2009. PMID: 19638912. DOI: 10.1097/SLA.0b013e3181b13ca2

23 Nakachi K, Konishi M, Ikeda M, Mizusawa J, Eba J, Okusaka T, Ishii H, Fukuda H and Furuse J: Hepatobiliary and Pancreatic Oncology Group of the Japan Clinical Oncology Group. A randomized Phase III trial of adjuvant S-1 therapy $v s$. observation alone in resected biliary tract cancer: Japan Clinical Oncology Group Study (JCOG1202, ASCOT). Jpn J Clin Oncol 48(4): 392-395, 2018. PMID: 29462482. DOI: 10.1093/ jjco/hyy004

24 Yanagimoto H, Toyokawa H, Sakai D, Wada H, Satoi S, Yamamoto T, Nagano H, Toyoda M, Ajiki T, Satake H, Tsuji A, Miyamoto A, Tsujie M, Takemura S, Yanagihara K and Ioka T: A phase I study for adjuvant chemotherapy of gemcitabine plus S-1 in patients with biliary tract cancer undergoing curative resection without major hepatectomy (KHBO1202). Cancer Chemother Pharmacol 81(3): 461-468, 2018. PMID: 29305639. DOI: $10.1007 / \mathrm{s} 00280-017-3513-4$

25 Kainuma O, Miura F, Furukawa D, Yamamoto H, Cho A, Sano $\mathrm{K}$, Nakagohri $\mathrm{T}$ and Asano T: Feasibility and efficacy of gemcitabine plus cisplatin combination therapy after curative resection for biliary tract cancer. J Hepatobiliary Pancreat Sci 22(11): 789-794, 2015. PMID: 26234468. DOI: 10.1002/jhbp.283

26 Gill JC, Endres-Brooks J, Bauer PJ, Marks WJ Jr and Montgomery RR: The effect of $\mathrm{ABO}$ blood group on the diagnosis of von Willebrand disease. Blood 69(6): 1691-1695, 1987. PMID: 3495304.

27 Souto JC, Almasy L, Muñiz-Diaz E, Soria JM, Borrell M, Bayén L, Mateo J, Madoz P, Stone W, Blangero J and Fontcuberta J: Functional effects of the $\mathrm{ABO}$ locus polymorphism on plasma levels of von Willebrand factor, factor VIII, and activated partial thromboplastin time. Arterioscler Thromb Vasc Biol 20(8): 20242028, 2000. PMID: 10938027. DOI: 10.1161/01 atv.20.8.2024

28 Marfia G, Navone SE, Fanizzi C, Tabano S, Pesenti C, Abdel Hadi L, Franzini A, Caroli M, Miozzo M, Riboni L, Rampini P and Campanella R: Prognostic value of preoperative von Willebrand factor plasma levels in patients with glioblastoma. Cancer Med 5(8): 1783-1790, 2016. PMID: 27236861. DOI: 10.1002/cam4.747

29 Barbalic M, Dupuis J, Dehghan A, Bis JC, Hoogeveen RC, Schnabel RB, Nambi V, Bretler M, Smith NL, Peters A, Lu C, Tracy RP, Aleksic N, Heeriga J, Keaney JF Jr, Rice K, Lip GY, Vasan RS, Glazer NL, Larson MG, Uitterlinden AG, Yamamoto J, Durda P, Haritunians T, Psaty BM, Boerwinkle E, Hofman A, Koenig W, Jenny NS, Witteman JC, Ballantyne C and Benjamin EJ: Large-scale genomic studies reveal central role of $\mathrm{ABO}$ in sP-selectin and sICAM-1 levels. Hum Mol Genet 19(9): 1863-1872, 2010. PMID: 20167578. DOI: 10.1093/hmg/ ddq061

30 Paterson AD, Lopes-Virella MF, Waggott D, Boright AP, Hosseini SM, Carter RE, Shen E, Mirea L, Bharaj B, Sun L and Bull SB; Diabetes Control and Complications Trial/Epidemiology of Diabetes Interventions and Complications Research Group: Genome-wide association identifies the $\mathrm{ABO}$ blood group as a major locus associated with serum levels of soluble E-selectin. Arterioscler Thromb Vasc Biol 29(11): 1958-1967, 2009. PMID: 19729612. DOI: 10.1161/ATVBAHA.109.192971

31 Paré G, Chasman DI, Kellogg M, Zee RY, Rifai N, Badola S, Miletich JP and Ridker PM: Novel association of ABO histoblood group antigen with soluble ICAM-1: results of a genomewide association study of 6,578 women. PLoS Genet 4(7): e1000118, 2008. PMID: 18604267. DOI: 10.1371/journal. pgen. 1000118

32 Zhang W, Xu Q, Zhuang Y and Chen Y: Novel association of soluble intercellular adhesion molecule 1 and soluble P-selectin with the ABO blood group in a Chinese population. Exp Ther Med 12(2): 909-914, 2016. PMID: 27446295. DOI: 10.3892/ etm.2016.3347

33 Duan YF, Zhu F, Li XD, An Y, Zhang H, Zhou Y, Zhang X and Jiang Y: Association between ABO gene polymorphism (rs505922) and cancer risk: a meta-analysis. Tumour Biol 36(7): 5081-5087, 2015. PMID: 25656610. DOI: 10.1007/s13277-0153159-y

34 Nakao M, Matsuo K, Hosono S, Ogata S, Ito H, Watanabe M, Mizuno N, Iida S, Sato S, Yatabe Y, Yamao K, Ueda R, Tajima $\mathrm{K}$ and Tanaka $\mathrm{H}$ : $\mathrm{ABO}$ blood group alleles and the risk of pancreatic cancer in a Japanese population. Cancer Sci 102(5): 1076-1080, 2011. PMID: 21306478. DOI: 10.1111/j.13497006.2011.01907.x

35 Krawczyk M, Mihalache F, Höblinger A, Acalovschi M, Lammert $\mathrm{F}$ and Zimmer V: Pancreatic cancer risk variant $\mathrm{ABO}$ rs505922 in patients with cholangiocarcinoma. World J Gastroenterol 17(41): 4640-4642, 2011. PMID: 22147973. DOI: 10.3748/wjg.v17.i41.4640

36 Coon JS and Weinstein RS: Blood group-related antigens as markers of malignant potential and heterogeneity in human carcinomas. Hum Pathol 17(11): 1089-1106, 1986. PMID: 3533753. DOI: 10.1016/s0046-8177(86)80413-0

37 Lee JS, Ro JY, Sahin AA, Hong WK, Brown BW, Mountain CF and Hittelman WN: Expression of blood-group antigen A - a 
favorable prognostic factor in non-small-cell lung cancer. N Engl J Med 324(16): 1084-1090, 1991. PMID: 1848917. DOI: 10.1056/NEJM199104183241603

38 Minato H, Nakanuma Y and Terada T: Expression of blood group-related antigens in cholangiocarcinoma in relation to nonneoplastic bile ducts. Histopathology 28(5): 411-419, 1996. PMID: 8735716. DOI: 10.1046/j.1365-2559.1996.343384.x

39 D'Andrea D, Moschini M, Soria F, Gust KM, Briganti A, Karakiewicz PI, Rouprêt M and Shariat SF: ABO blood group and Rhesus factor are not associated with outcomes after radical cystectomy for non-metastatic urothelial carcinoma of the bladder. Anticancer Res 37(10): 5747-5753, 2017. PMID: 28982896. DOI: 10.21873/anticanres.12014

Received February 15, 2020

Revised March 30, 2020

Accepted March 31, 2020 